\title{
Interannual and Decadal Cycles in River Flows of Southeastern South America
}

\author{
Andrew W. Robertson* And Carlos R. Mechoso \\ Department of Atmospheric Sciences, University of California, Los Angeles, Los Angeles, California
}

(Manuscript received 12 May 1997, in final form 12 November 1997)

\begin{abstract}
The time series of annual streamflow of four rivers in southeastern and south-central South America (the Negro, Paraguay, Paraná, and Uruguay Rivers) for the period 1911-93 are analyzed. Application of the multitaper method shows that the following features are significant at the 95\% level: 1) a nonlinear trend, 2) a near-decadal component, and 3) interannual peaks with ENSO timescales. The trend and near-decadal components are most marked in the two more central rivers, the Paraguay and Paraná, with ENSO timescale variability most pronounced in the Negro and Uruguay rivers in the southeast. Composites of SST are made for each of the statistically significant oscillatory components of river flow, by reconstructing each component using singular spectrum analysis. These composites confirm the influence of ENSO on the streamflow variability of the Negro and Uruguay Rivers, with El Niño associated with enhanced streamflow. On the decadal timescale, high river runoff is associated with anomalously cool SSTs over the tropical North Atlantic. A very similar near-decadal oscillation in SST over this region is identified separately from a rotated empirical orthogonal function analysis of gridded annual mean SSTs. The near-decadal component of the Paraguay and Paraná Rivers is strongest in the austral summer.
\end{abstract}

\section{Introduction}

The Negro, Paraguay, Paraná, and Uruguay Rivers form an extensive river system that drains most of southeastern South America east of the Andes, between $15^{\circ}$ and $35^{\circ} \mathrm{S}$, reaching the Atlantic at the La Plata estuary. These four rivers have recently been found to exhibit a secular trend over the twentieth century, with river flows tending to decrease until midcentury, and to increase strongly thereafter (Genta et al. 1998; Garcia and Vargas 1997). On interannual timescales, the precipitation in this region is known to be related to the El NiñoSouthern Oscillation (ENSO) (Ropelewski and Halpert 1987, 1989, 1996; Aceituno 1988; Pisciottano et al. 1994; Diaz et al. 1998). Mechoso and Perez-Iribarren (1992) have documented a relationship between streamflow in the Negro and Uruguay Rivers and the Southern Oscillation (SO): there is a clear tendency toward belowaverage streamflow in high SO (La Niña) years from June to December, and a slight tendency toward aboveaverage flows in low SO (El Niño) years from November

\footnotetext{
* Additional affiliation: Institute of Geophysics and Planetary Physics, University of California, Los Angeles, Los Angeles, California.

Corresponding author address: Dr. Andrew W. Robertson, Dept. of Atmospheric Sciences, UCLA, 405 Hilgard Ave., Los Angeles, CA 90095-1565.

E-mail: andy@atmos.ucla.edu
}

through the following February. Southeastern South America is also one of the principal regions of the globe where land surface temperatures have been increasing since 1900, and the region shows secular, decadal, interdecadal, as well as strong ENSO timescale temperature fluctuations (Mann and Park 1994).

Coherent interannual-to-secular variations in global sea surface temperatures (SSTs) over the past century are becoming increasingly well documented. The strongest signal is a spatially irregular trend, characterized by overall warming during 1910-40 and since 1975, with cooling in between, especially over the Northern Hemisphere. Substantial cooling prevailed over the North Pacific between 1950 and 1980, and continues over the North Atlantic today (Moron et al. 1997). A near-decadal fluctuation has been found over the North Atlantic (Deser and Blackmon 1993; Moron et al. 1997), with interdecadal variability throughout the tropical and North Pacific and Indian Oceans (Allen and Smith 1994; Deser and Blackmon 1995; Zhang et al. 1997), and South Atlantic (Venegas et al. 1996; Moron et al. 1997). In the tropical Atlantic, a cross-equatorial dipolar SST anomaly pattern with a period of $12-13 \mathrm{yr}$ has been identified, together with a $9-10$-yr period over the tropical North Atlantic (Allen and Smith 1994; Mehta 1998). ENSO exhibits a broad 2-6-yr interannual spectral peak with large influence throughout the Tropics, as well as the North and South Pacific Oceans (Allen and Smith 1994; Kawamura 1994; Moron et al. 1997) and the South Atlantic (Venegas et al. 1996).

River flow variations in southeastern South America 
may be related to some of the same climatic oscillations that underlie those in SST. The aim of this paper is to examine the spectra of streamflow variations in the $\mathrm{Ne}$ gro, Paraguay, Paraná, and Uruguay Rivers for the period 1911-93, to explore the existence of statistically significant oscillatory components with interannual-tosecular periods, and to attempt to relate these components to variations in SST.

Two complementary methods of spectral analysisthe multitaper method (MTM) and singular-spectrum analysis (SSA) - are employed to isolate spectral peaks, assess their statistical significance, and reconstruct the underlying oscillatory components. Brief descriptions of the methods are given in section 2. In section 3 we analyze the spectrum of the combined Negro-Uruguay annual river discharge. Oscillatory components with periods of about 3.5 and $6.0 \mathrm{yr}$ are found, for which we construct global composites of SST from the GISST2 dataset (Rayner et al. 1995) to depict associated nonlocal climate variations. In section 4 we analyze the combined Paraguay-Paraná River discharge, where, in addition, a rotated empirical orthogonal function (EOF) analysis is applied to near-global SSTs from 1911 to 1993. A neardecadal $(9.0 \mathrm{yr})$ component is isolated both in the Paraguay-Paraná River flow and in SSTs over the tropical North Atlantic and south of Greenland. A discussion follows in section 5 .

\section{Datasets and analysis methods}

The four rivers divide geographically into two pairs. The Negro and Uruguay Rivers drain a relatively small catchment $\left(0.5 \times 10^{6} \mathrm{~km}^{2}\right)$, situated mostly within Uruguay and southeastern Brazil $\left(25^{\circ}-35^{\circ} \mathrm{S}\right)$, with both rivers draining into the La Plata estuary to the south. The Negro and Uruguay Rivers were measured at Rincón del Bonete $\left(33^{\circ} \mathrm{S}, 56^{\circ} \mathrm{W}\right)$ and Salto Grande $\left(31^{\circ} \mathrm{S}\right.$, $\left.58^{\circ} \mathrm{W}\right)$, respectively. The Paraguay and Paraná Rivers drain a much larger area $\left(2.1 \times 10^{6} \mathrm{~km}^{2}\right)$, mostly to the north. Their drainage basin is bounded approximately by the Andes to the west, the Atlantic Ocean to the east, and extends northward to near $15^{\circ} \mathrm{S}$. Streamflows in the Paraná and Paraguay Rivers were measured at Posadas $\left(27^{\circ} \mathrm{S}, 56^{\circ} \mathrm{W}\right)$ and Puerto Bermejo $\left(27^{\circ} \mathrm{S}\right.$, $58^{\circ} \mathrm{W}$ ), respectively, upstream of confluence of the two rivers. More details of the drainage basins and measuring station locations are given in Genta et al. (1998).

We consider two-river averages for each pair of rivers, which permits some smoothing of interriver variations, while retaining the main regional differences. Streamflows in the Paraná and Paraguay Rivers were measured using the same method over whole length of the record. A quality control of these streamflow records was performed by N. O. Garcia, who also provided us with the data (see Garcia and Vargas 1997). Dams were built on the Negro and Uruguay Rivers in 1939 and 1980, respectively, so the methods used to estimate streamflows differ before and after these dates. The equivalent un- impeded river flow of a dammed river is calculated by engineers, who estimate evaporation and seepage from the reservoir behind the dam. Interannual flow variations are found to dominate the Negro-Uruguay flow series. While evaporation from a reservoir is sensitive to temperature, and thus may amplify or attenuate an interannual flow signal, the latter is unlikely to be an artifact of dam construction.

To focus on interannual-to-secular variations, the monthly mean streamflow data for the period 1911-93 were annually averaged. Annual-mean streamflow integrates short-term subannual variability and can be a highly suitable parameter to study climate change, provided nonclimatic anthropogenic effects can be neglected. Its consideration is further motivated by the economic and societal implications of potential long-term predictability. Total precipitation is rather evenly distributed throughout the calendar year in southeastern South America (Diaz et al. 1998), although the mean annual cycles of the four rivers show substantial differences. The flow of the Paraná peaks in early austral fall, and the Negro and Uruguay in austral winterspring. In constructing the annual flow anomalies for each river pair, the flow of each individual river was firstly normalized by its standard deviations to give each river equal weight. No additional temporal smoothing was used. The principal features of the spectra of the individual rivers were not found to deviate much from those of the two-river averages.

Our primary tool for detecting significant spectral peaks in the short time series available is the MTM (Thomson 1982; Percival and Walden 1993). In contrast to the classic Blackman-Tukey correlogram method where a unique spectral window or "taper" is used, MTM uses a small set of optimal window functions (tapers) to reduce the variance of the spectral estimate. A set of independent estimates of the power spectrum are computed by premultiplying the time series by orthogonal tapers, which are chosen to minimize the spectral leakage that arises due to the finite length of the time series. Averaging over this ensemble of spectra yields a better and more stable estimate than do singletaper methods (Thomson 1990; Mann and Lees 1996). Statistical significance is determined against a red noise null hypothesis using a chi-squared test. The null hypothesis spectrum is determined by fitting an analytical first-order autoregressive [AR(1)] spectrum to the smoothed MTM spectrum of the time series; the smoothing uses a median filter to remove narrowband "signals," which would otherwise distort the noise null hypothesis (Mann and Lees 1996).

Having identified a significant spectral peak, we then use SSA (Vautard and Ghil 1989; Vautard et al. 1992) to reconstruct the underlying oscillatory components of the time series. Unlike MTM, which has its roots in the Fourier transform, SSA is based on an eigenvector decomposition of the autocorrelation matrix, making the effective "filters" highly data adaptive. Calculations in 


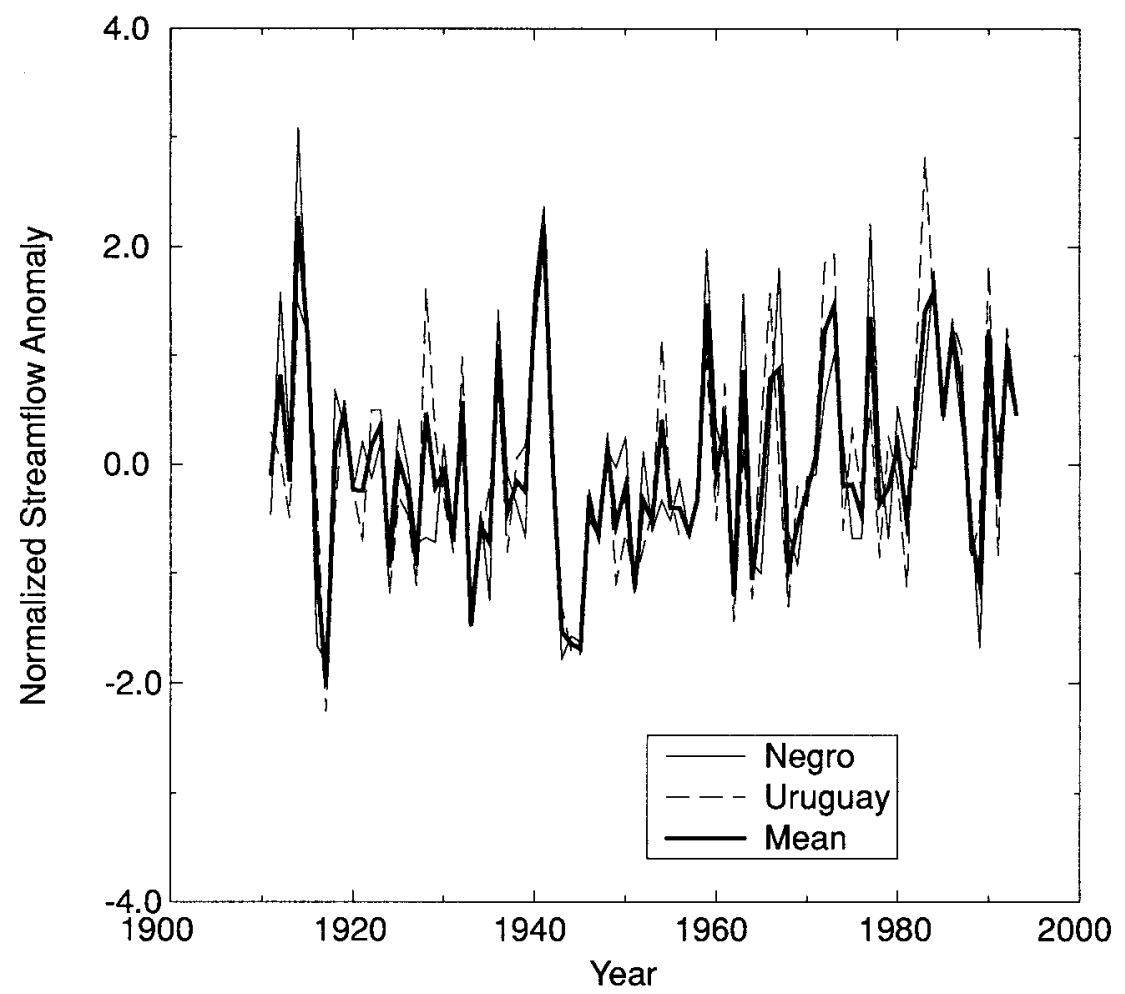

Fig. 1. Annual-mean stream flow anomalies relative to the 1911-93 time mean, normalized by their standard deviation (nondimensional). Negro River (thin solid), Uruguay River (thin dashed), and the Negro-Uruguay arithmetic mean (thick solid).

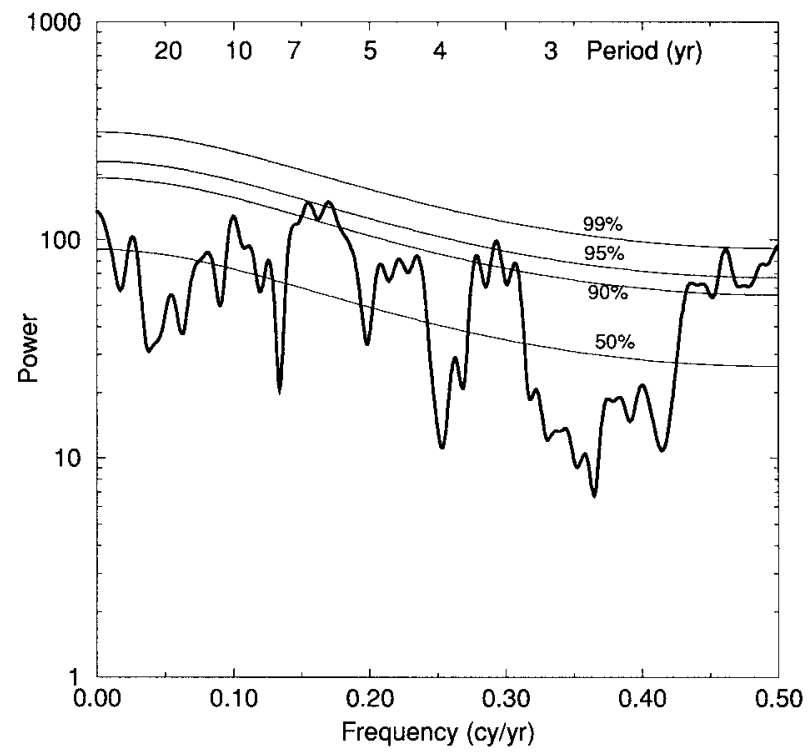

FIG. 2. Multitaper spectrum of the Negro-Uruguay annual streamflow time series. Two tapers were used, giving a half-bandwith spec-

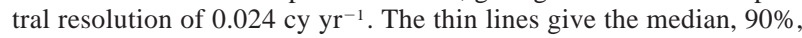
$95 \%$, and $99 \%$ significance levels against a red-noise null hypothesis. Significant peaks at the $95 \%$ level are centered at $0.170,0.293$, and $0.461 \mathrm{cy} \mathrm{yr}^{-1}$. this paper use the Toeplitz form of the autocorrelation matrix (Vautard et al. 1992). Spectral peaks are associated with oscillatory pairs of eigenvectors, from which the oscillatory part of the time series can be reconstructed. A significance test of the oscillatory pairs can be made against a red noise null hypothesis using a chisquared test or a Monte Carlo method (Allen and Smith 1996). Again a first-order autoregressive process is fit to the time series to generate the null-hypothesis, but unlike MTM, the lag-1 autocorrelation associated with any "signal" is also included, effectively reddening the null hypothesis and making it more difficult to reject. We use the methodology of Allen and Smith (1996) to partially circumvent this problem, whereby once a component has been identified as significant, it can then be explicitly included in the null hypothesis. The latter is then "red noise plus given oscillatory components." We use the chi-squared test for all estimates of significance. Both methods were implemented using the SSA-MTM toolkit of Dettinger et al. (1995) and Ghil et al. (1997, personal communication).

\section{The Negro and Uruguay Rivers}

Figure 1 illustrates the annual streamflow anomalies of the Negro and Uruguay Rivers, together with the tworiver average. The multitaper spectrum of the latter is 


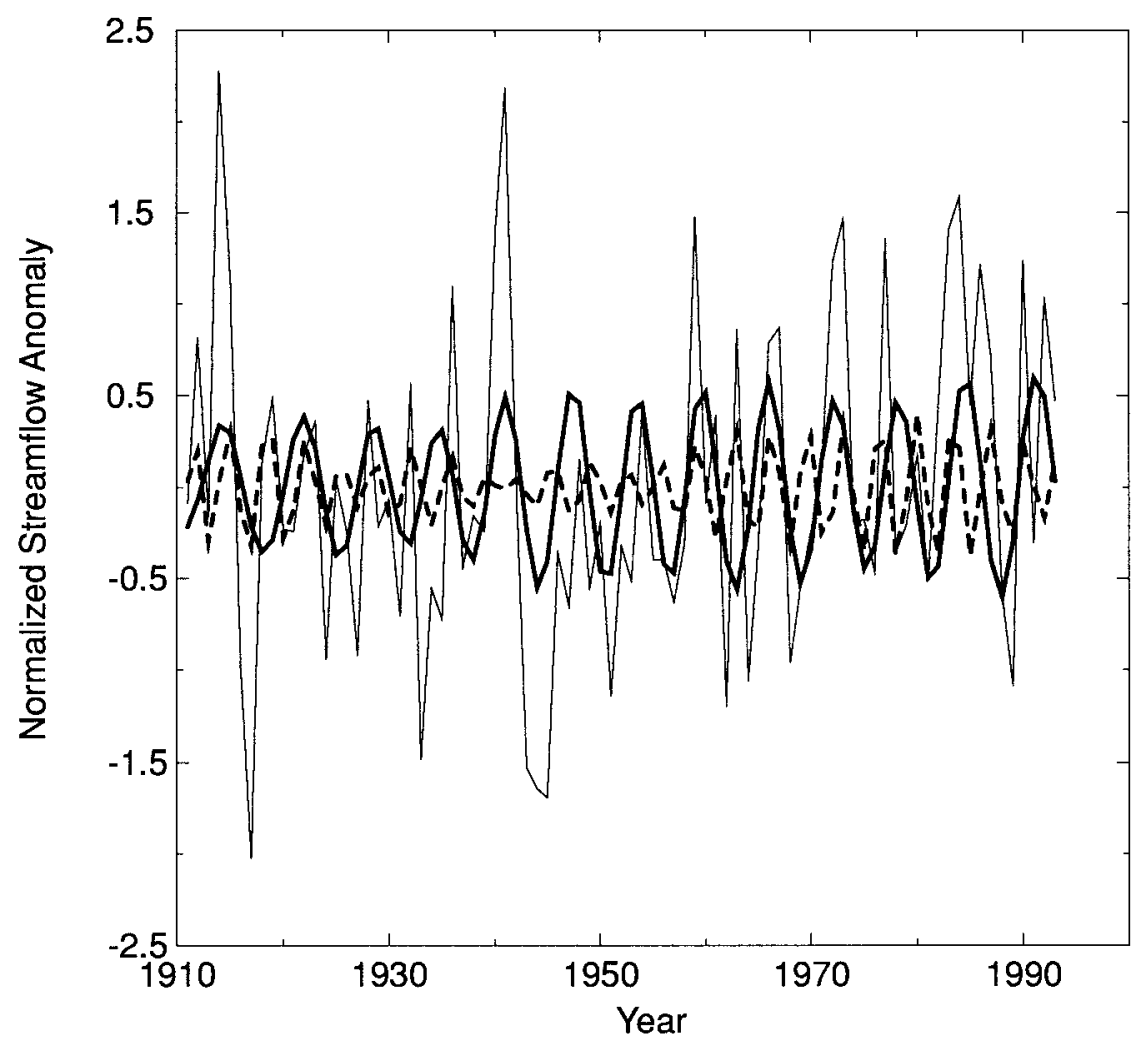

FIG. 3. Reconstructed components (RCs) of Negro-Uruguay time series, derived using SSA with a 30 -yr window. RCs $1-2(T=6.3 \mathrm{yr}$; thick solid $)$, RCs $8-9(T=3.5 \mathrm{yr}$; thick dashed $)$, and unfiltered time series (thin solid), where $T$ refers to the approximate period of the oscillation.

shown in Fig. 2, using $p=2$ tapers. For the 83-point time series, this choice of tapers allows a half-bandwidth spectral resolution of $p f_{R}=0.024 \mathrm{cy} \mathrm{yr}^{-1}$ [where $f_{R}=$ $1(83 \mathrm{yr})^{-1}$ is the Rayleigh frequency], at the expense of a larger variance in the spectral estimate. Spectral peaks, significant at the $95 \%$ level against a red noise null hypothesis, occur at periods of 5.9, 3.4, and $2.2 \mathrm{yr}$. Similar periods have been isolated over the Pacific and attributed to ENSO, while the latter is known to influence the Negro and Uruguay Rivers (Mechoso and Perez-Iribarren 1992). Quasi-biennial and quasi-quadrennial periods have been found over the Pacific in equatorial SSTs and zonal winds (Jiang et al. 1995) and tropical SSTs (Moron et al. 1997), while a near 6-yr period has been identified in North Pacific SSTs (Robertson 1996) and sea level (Unal and Ghil 1995).

To analyze these peaks further and to obtain an independent estimate of their significance, reconstructed components (RCs) are calculated independently using SSA. Using a lag window of $M=30$ years, the two leading SSA eigenmodes form an oscillatory pair with a dominant period of $6.3 \mathrm{yr}$, which accounts for $17.1 \%$ of the variance of the time series. The annual sampling is inadequate to properly resolve the quasi-biennial peak, and is marginal for the quasi-quadrennial one, but SSA eigenvectors 8 and 9 do form an oscillatory pair with a dominant period of $3.5 \mathrm{yr}$ (9.4\% variance). The 3.5- and 6.3-yr oscillatory components compare closely with those found using MTM. Using a chi-squared test (Allen and Smith 1996), the 6.3-yr SSA pair is statistically significant against a red noise null hypothesis at the $95 \%$ level using $M=40 \mathrm{yr}$ (i.e., an approximate spectral resolution of $1 / M=0.025 \mathrm{cy} \mathrm{yr}^{-1}$ ). The 3.5yr mode is significant at the $80 \%$ level using $M=30$, provided the 6.3-yr pair is included in the null-hypothesis. This lower level of significance may be attributable to inadequate sampling at the annual resolution. However, both SSA pairs do pass the oscillatory pairing criteria of Vautard et al. (1992) and since their periods approximately correspond to those found using MTM, the results of the two independent methods taken together provide strong evidence that these spectral peaks-near 3.5 and $6.0 \mathrm{yr}$ - are real. The annual resolution used here is not sufficient to consider the quasibiennial component in detail.

Reconstructed components $1-2$ and 8-9 are plotted in Fig. 3, along with the unfiltered time series. These $\mathrm{RC}$ pairs are narrowband-filtered versions of the time series, where the filters are determined from the time series itself so as to maximize the explained variance and are thus data adaptive. Together, these components account for $26.5 \%$ of the unfiltered variance. 
(a) RCs 1-2 (6.3yr)

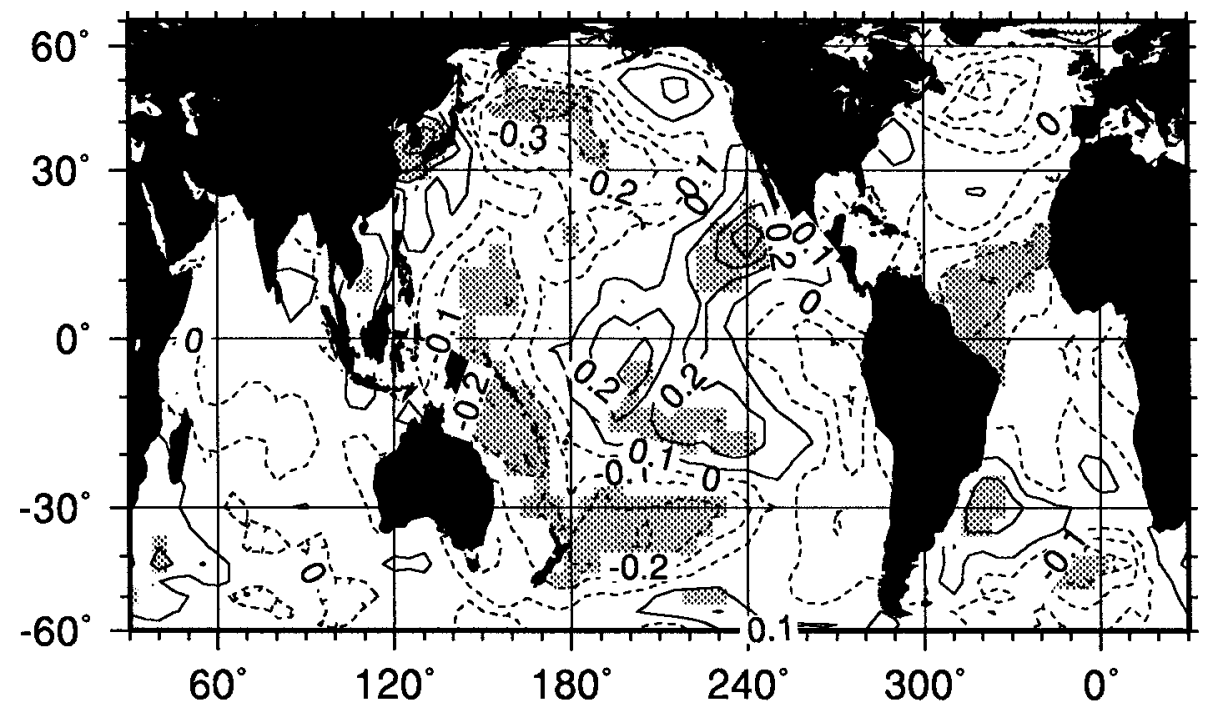

(b) RCs 8-9 (3.5yr)

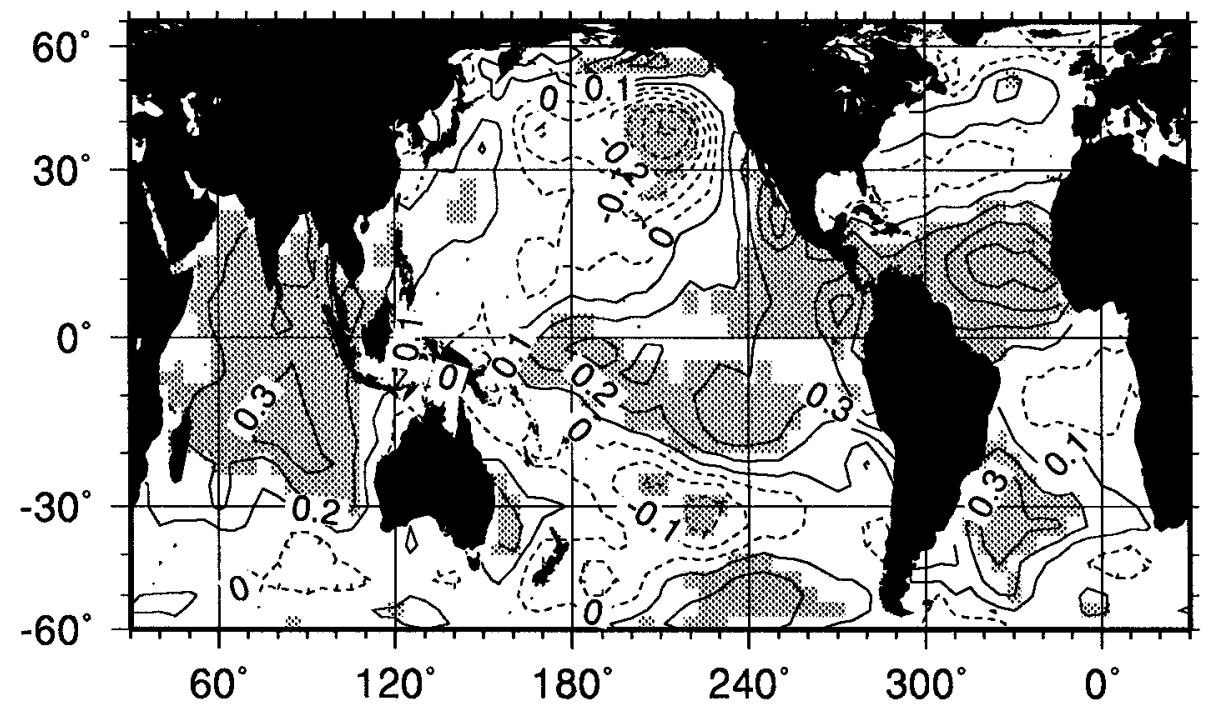

FIG. 4. Composites of SST (annual means) for positive-minus-negative extrema of (a) RCs 1-2, and (b) RCs $8-9$ (contour interval, $0.1^{\circ} \mathrm{C}$ ). All years in which the RC pairs in Fig. 3 exceed \pm 1 standard deviation are included. The stippled regions are locally significant at the 95\% level (two-sided $t$ test with 24 degrees of freedom).

The RCs are now used as indices to assess concurrent variations in global SSTs. We composite SSTs for all years in which the RC pair has an amplitude exceeding one standard deviation and take the difference between the positive and negative composites thus obtained. The resulting high-minus-low composites are shown in Fig. 4 , together with a two-tailed Student's $t$ test on the difference between means, at each grid point. For the $t$ test, it is important to take serial correlation into account
(Zwiers and von Storch 1995), and the number of degrees of freedom $N+M-2$ was taken to be 24 in both cases. Here, $N$ and $M$ are the effective sizes of the positive and negative composites, respectively, with each taken to be 83/6.3 $\sim 13$.

The 6.3-yr oscillatory component of the Negro-Uruguay time series is associated with significant SST anomalies over areas of the central and western Pacific, as well as over the tropical North Atlantic. Although 
the regions of statistically significant anomalies are rather small, the spatial structure of the former bears some similarities to that of the interdecadal Pacific variability identified by Wang (1995) and Latif et al. (1997), characterized by SST anomalies straddling the equator in a v shape. The symmetry about the equator of extratropical anomalies in the Pacific suggests that equatorial dynamics is involved. Over the Atlantic, there are negative SST anomalies north of the equator and positive ones off the coast of southeastern South America.

The 3.5-yr component is clearly associated with ENSO over the Pacific, with the characteristic antiphase relationship between the tropical and extratropical $\mathrm{Pa}-$ cific. There are 15 positive peaks of the 3.5-yr component in Fig. 3 that exceed one standard deviation. Of these, 10 coincide either with a warm-episode year in the equatorial Pacific, or with the year following a warm episode. The list of warm-episode years was taken from Rasmussen and Carpenter (1983, their Table 2) for the period up to 1980 . The warm phase of ENSO is accompanied by anomalously high streamflows, consistent with the results of Mechoso and Perez-Iribarren (1992). Above-average streamflows are also concurrent with large positive SST anomalies over the Indian Ocean, tropical North Atlantic, and southwestern Atlantic. Each is a characteristic feature of composites of El Niño years, although the amplitudes found here in these regions are larger relative to those in the equatorial eastern Pacific. The polarity of the SST anomalies over the tropical North Atlantic is opposite in the two modes in Fig. 4, and we shall return to this feature after discussing the Paraguay and Paraná Rivers.

\section{The Paraguay and Paraná Rivers}

Figure 5 illustrates the annual streamflow anomalies of the Paraguay and Paraná Rivers and the two-river average. The large annual anomaly in 1983 is associated with the exceptional El Niño of 1982-83. However, the time series exhibit larger low-frequency variability than the Negro and Uruguay Rivers, and this is brought out in the multitaper spectrum in Fig. 6. The trend $(T>40$ yr, with two tapers), and an 8.8-yr period pass the MTM $95 \%$ significance level against red noise. While there is also some variability on ENSO timescales, the spectrum is dominated by longer-period variability.

When SSA is applied to the Paraguay-Paraná time series, the trend is well captured by the two leading eigenmodes, which account for $25.3 \%$ of the variance (using an $M=40 \mathrm{yr}$ lag window). To identify further peaks, this trend was subtracted from the time series, prior to repeating the SSA with $M=30$ [the smaller value of $M$ allows greater modulation of the signal over time (see Vautard et al. 1992)]. The two leading SSA eigenmodes of the detrended time series form an oscillatory pair with a $9.0-y r$ period that accounts for $21.4 \%$ of the variance of the detrended time series (i.e., $16.0 \%$ of the total variance). This near-decadal com- ponent is very similar in period to that found using MTM (8.8 and $9.0 \mathrm{yr}$, respectively). Both SSA pairs are statistically significant at the $95 \%$ level with $M=40$ [the trend with respect to an $\mathrm{AR}(1)$ null hypothesis, and the near-decadal mode with respect to a null hypothesis consisting of this trend plus AR(1) noise].

The SSA reconstructed components associated with the trend and near-decadal period are shown in Fig. 7. The trend component falls gradually until around 1960, and then increases rapidly until about 1980, consistent with the trend analysis of the individual rivers using 30yr running means by Genta et al. (1998), and then levels off. The midcentury minimum coincides approximately with that of the second secular mode of global surface temperatures (the first is an upward trend) found by Mann and Park (1994) and may be associated with a combination of both. The near-decadal component is present throughout the time series, but with weaker amplitude around the middle of the century; the large swings in streamflow 1910-30 are associated quite clearly with this component.

In an attempt to trace the origin of the near-decadal oscillatory component of the Paraguay-Paraná time series, we have analyzed the variability in global SSTs using a rotated EOF analysis, similar to that performed by Kawamura (1994), but for the longer 1911-93 gridded SST $\left(60^{\circ} \mathrm{N}-50^{\circ} \mathrm{S}\right)$ annual-mean time series from the GISST2 dataset. A near-global domain is chosen in order to identify possibly global-scale SST anomalies that accompany riverflow variations in southeastern South America. An orthogonal varimax rotation was applied to the leading four EOFs of the GISST, which account for $50 \%$ of the variance; varimax minimizes the spatial extent of regions with strong correlations between the newly found (rotated) EOFs and the original SST anomaly time series. The rotated EOFs (Fig. 8) have more localized structures than the unrotated EOFs, and thus they may be more amenable to physical interpretation (e.g., Richman 1986). Similar structures were obtained by rotating six EOFs, although the ENSO mode starts to become artificially fragmented.

Figures 8 and 9 show the rotated EOFs and principal components (PCs), respectively, where the latter are normalized to unit standard deviation and the EOFs are dimensional with amplitude corresponding to unit standard deviation of the PC. Rotated PCs 1 and 3 of SST contain large trend components, whereas PC 2 is dominated by ENSO. The multitaper spectra of all four PCs contain significant peaks at 3.4 yr and 5-6 yr. The MTM spectrum of PC 4 (Fig. 10) contains a significant peak at a period of $8.0 \mathrm{yr}$, which is close to the 8.8-yr MTM peak in the Paraguay-Paraná time series. SSA of rotated PC 4 identifies an oscillatory eigenmode pair (modes 3 and 4) with a period of 9.2 yr that accounts for $13.4 \%$ of the variance; it is statistically significant at the $90 \%$ level against a null hypothesis of AR(1) noise plus trend, with $M=40$.

The near-decadal reconstructed components of rotat- 


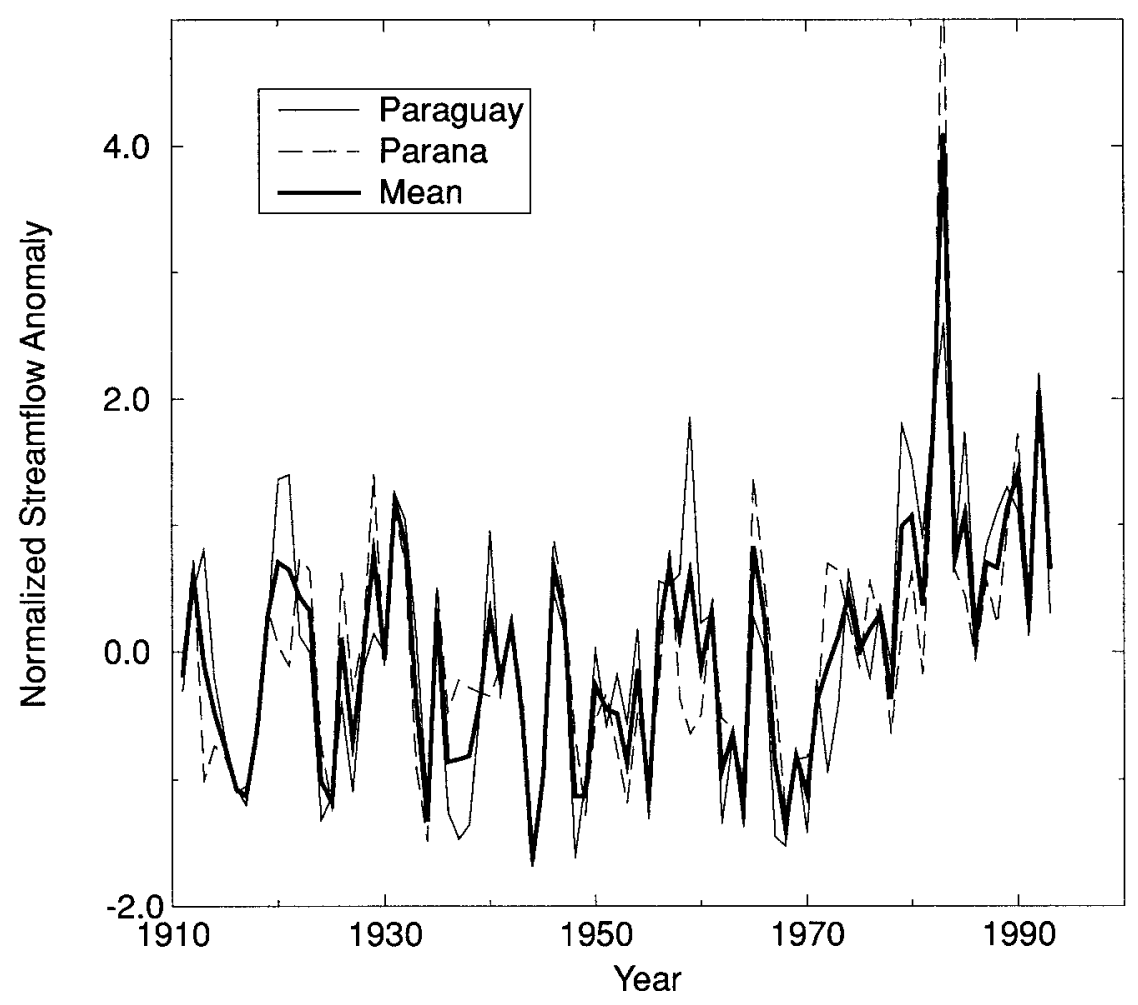

FIG. 5. Paraguay-Paraná annual mean streamflow 1911-93. As in Fig. 1.

ed PC 4 of SST are plotted in Fig. 11, superposed on those from the Paraguay-Paraná flow. Both reconstructions are very similar in both period and phase, suggesting that the two near-decadal cycles may be related. The correlation coefficient between them is 0.80 , which

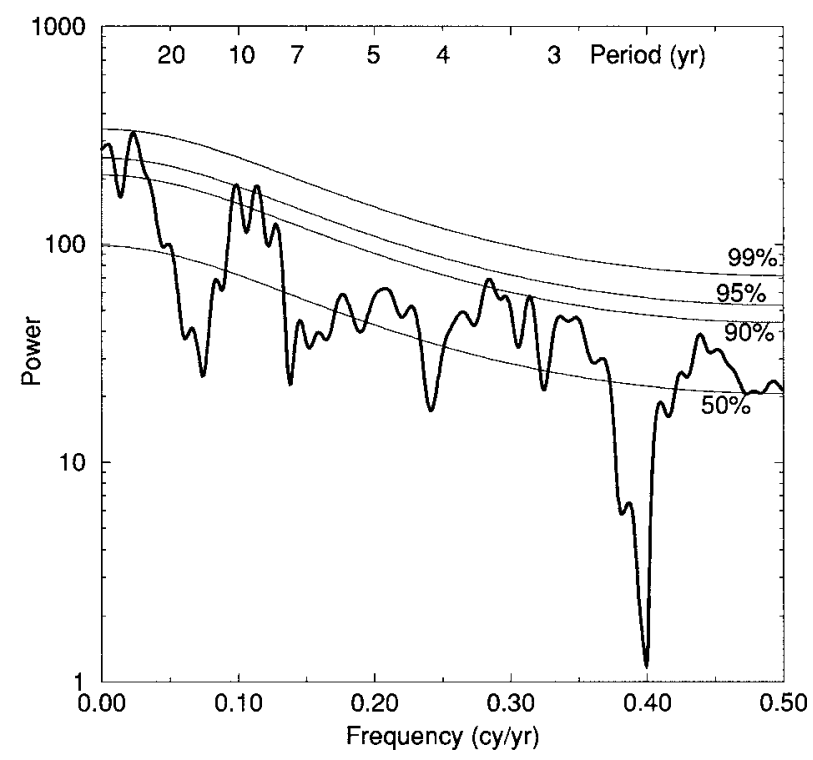

FIG. 6. Multitaper spectrum of Paraguay-Paraná time series. As in Fig. 2. Significant peaks at the $95 \%$ level are the trend and 0.113 cy $\mathrm{yr}^{-1}$ frequency. is statistically significant at the $95 \%$ level $\left(r_{95 \%}=0.70\right)$ with 8 degrees of freedom.

Composites of SST are shown in Fig. 12, constructed from each near-decadal RC in the same manner as in

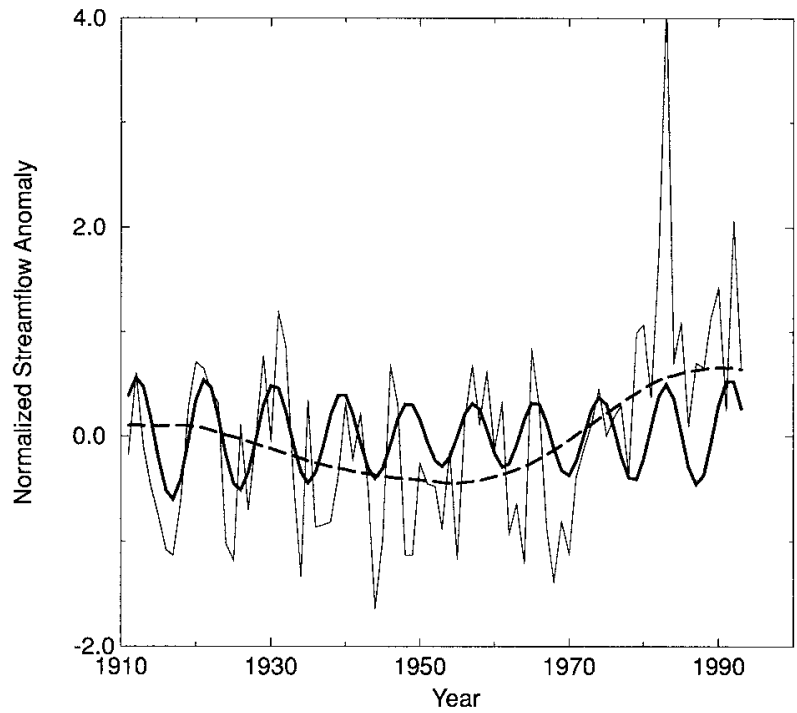

FIG. 7. Trend (thick solid) and decadal $(T=9.0 \mathrm{yr}$; thick dashed) RCs of Paraguay-Paraná time series, together with the unfiltered annual anomalies (thin solid). The trend is RCs 1-2 of an SSA of the unfiltered annual time series with a $40-\mathrm{yr}$ window. The decadal component is RCs 1-2 of an SSA of the detrended time series with a $30-y r$ window. Details as in Fig. 3. 
(a) EOF $1(15 \%)$

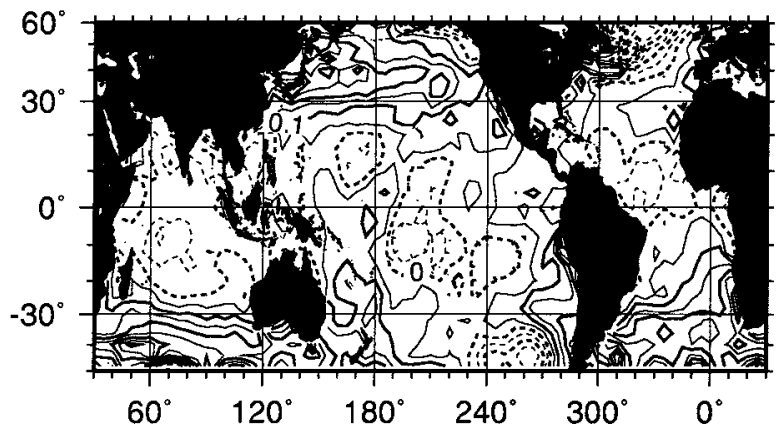

(c) EOF $3(12 \%)$

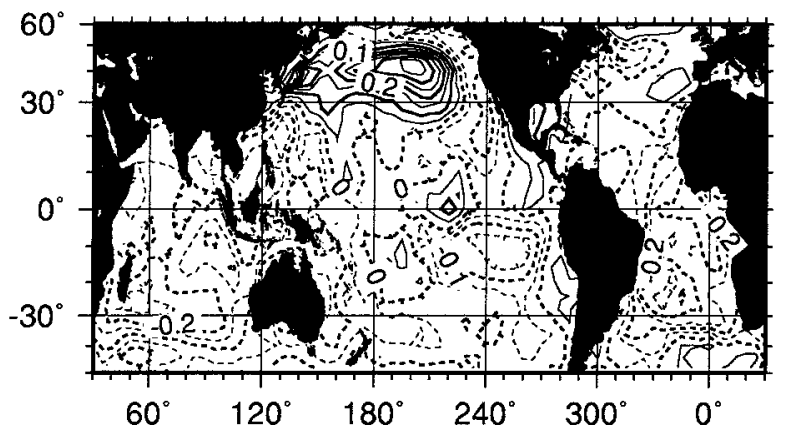

(b) EOF $2(13 \%)$

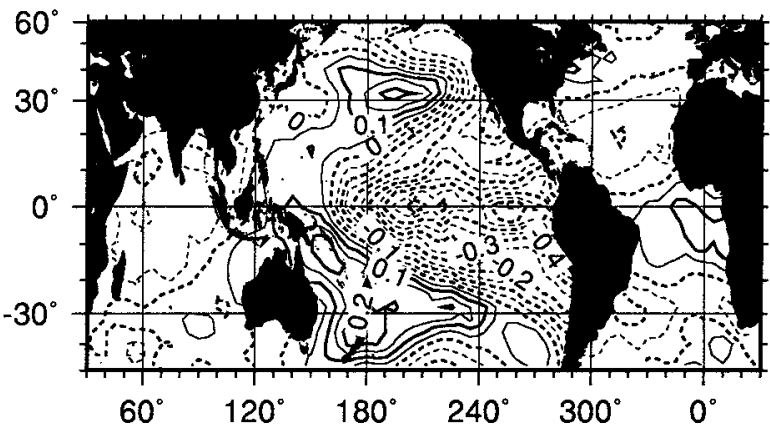

(d) EOF $4(10 \%)$

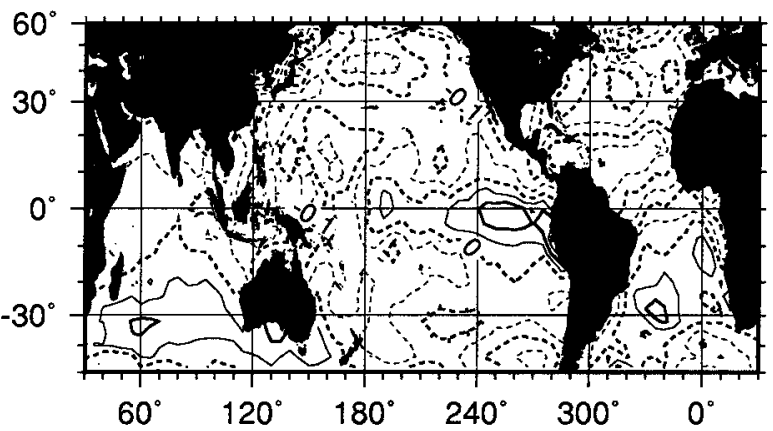

FIG. 8. Rotated EOFs of GISST annual mean SSTs $60^{\circ} \mathrm{N}-50^{\circ} \mathrm{S}, 1911-93$. Four EOFs were rotated using a varimax rotation. Contour interval is $0.05^{\circ} \mathrm{C}$, with amplitudes scaled to correspond to a one-standard deviation excursion of the principal component. Negative contours dashed. The variance accounted for by each mode is given in brackets.

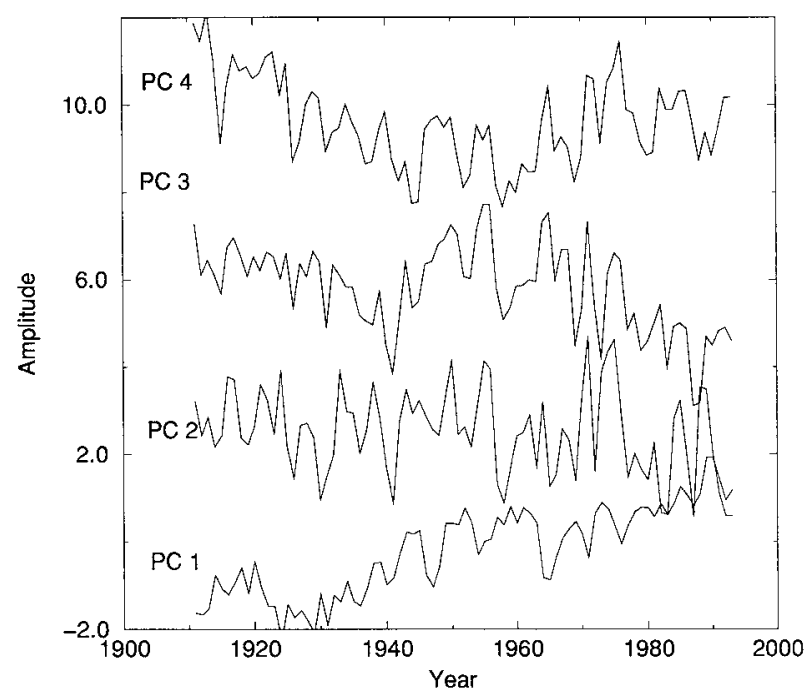

FIG. 9. Rotated principal component time series, normalized by their respective standard deviations. Each series is displaced along the ordinate for legibility.

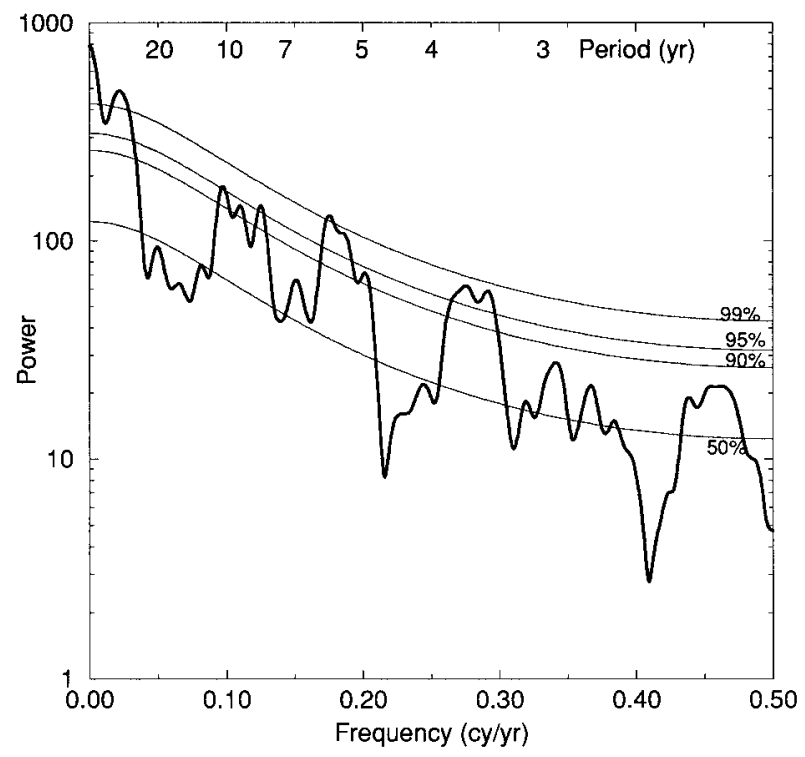

FIG. 10. Multitaper spectrum of GISST rotated principal component number 4 (PC 4); details as in Fig. 2. The trend and 0.125, 0.176,

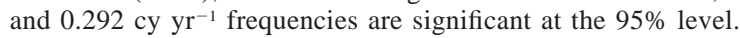




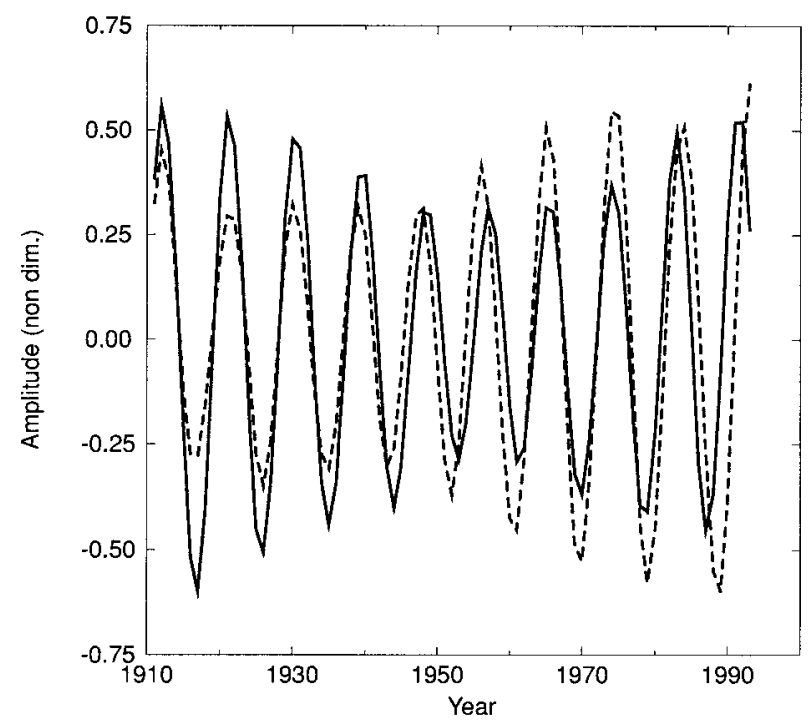

FIG. 11. Decadal RCs of Paraguay-Paraná time series (solid) and SST rotated PC 4 (dashed). Correlation coefficient between curves is 0.80 .

Fig. 4. The near-decadal component of SST (Fig. 12a) is strongest over the tropical and subtropical North Atlantic, and near Newfoundland. A mode of similar period and spatial structure has been documented by Allen and Smith (1994). Applying the same compositing procedure to the near-decadal component of the Paraguay and Paraná Rivers yields a similar pattern of statistically significant anomalies over the tropical North Atlantic and far North Atlantic (Fig. 12b). The similarity of Figs. $12 \mathrm{a}$ and $12 \mathrm{~b}$ provides further evidence that the neardecadal variability seen in the rivers and SST is related. Anomalously high streamflow in the Paraguay and Paraná Rivers is accompanied by significant negative SST anomalies over the tropical North Atlantic. This relationship was also found for the 6-yr component of the Negro-Uruguay time series (Fig. 4a) but is opposite in polarity to that of the 3.5-yr ENSO component (Fig. 4b).

To obtain an independent estimate of the covariability between the (unfiltered) Paraguay-Paraná River flow time series, and (unfiltered) annual-mean SSTs over the tropical North Atlantic, the cross spectrum between them was evaluated, using SSTs averaged over the region $0^{\circ}-20^{\circ} \mathrm{N}$ and $60^{\circ} \mathrm{W}-0^{\circ}$. The squared coherency and phase are plotted in Fig. 13. The squared coherency between the two series is statistically significant at the 95\% confidence level at periods of 8.5-10.7 yr, consistent with our MTM estimates in Figs. 6 and 10, and the SSA results in Fig. 12. The phase difference between the two time series is estimated to be about $1.2 \pi$, indicating a near-antiphase relationship, consistent with Figs. 8d and 11.

To examine the trend component, global gridded SSTs were regressed onto the trend component of the Paraguay-Paraná time series in Fig. 7. Although the result- ing regression coefficients are not statistically significant, the pattern (not shown) is similar to that found in the trend of global SSTs by Moron et al. (1997), with broad El Niño-like conditions in the tropical and extratropical Pacific associated with the upward trend in river flow, and a strong interhemispheric north-south dipole over the Atlantic Ocean with the negative center south of Greenland and the positive one east of southern Brazil. There are also large positive SST trends over the Southern Ocean, and over the Indian Ocean associated with increasing river flow in southeastern South America.

\section{Discussion}

We have presented evidence that the streamflows of four major rivers in southeastern South America have interannual cycles (at about 3.5 and 6 yr), a near-decadal cycle with period of approximately $9 \mathrm{yr}$, as well as a nonlinear trend. The interannual cycles are strongest in the Negro-Uruguay combined river time series (Fig. 3), with the decadal and trend components most pronounced in the combined Paraguay-Paraná flow (Fig. 7). Analyses of each river in turn yielded similar peaks to those documented above for the two-river averages. The interannual peaks are also found significant at the 90\% level in the Paraná River. In this paper we have focused on annual-mean streamflows, leaving a closer analysis of the short period interannual peaks with monthly data for further study.

Composite SST anomalies were constructed for each significant oscillatory component of river flow. The 3.5yr cycle in the Negro-Uruguay flow series shows a characteristic ENSO-like pattern in Pacific SST anomalies, with above-average streamflow in the rivers coinciding with the warm phase in the eastern equatorial Pacific (Fig. 4b). Aceituno (1988) has reported an eastward extension of low sea level pressure anomalies into southern South America during El Niño austral winters, with the South Pacific subtropical high weakened and displaced northward. Thus, on ENSO timescales, there is evidence that interannual atmospheric circulation anomalies over the Pacific sector directly influence southeastern South America. Air-sea interaction over the Atlantic may, however, also play a role since the positive phase of the 3.5-yr cycle in river flow also coincides with large and significant positive SST anomalies over the Atlantic, particularly off the coast of South America near $30^{\circ} \mathrm{S}$, and in the tropical North Atlantic; the latter has also been documented by Hastenrath et al. (1987), Aceituno (1988), and Enfield and Mayer (1997) in connection with El Niño.

The 6-yr cycle in the Negro-Uruguay streamflow shows a similar pattern in SST anomalies over the Pacific, except that the largest equatorial anomalies are situated in the central and western Pacific, with large off-equatorial anomalies farther east (Fig. 4a). This spatial pattern is characteristic of longer timescale vari- 


\section{(a) GISST RPC 4}

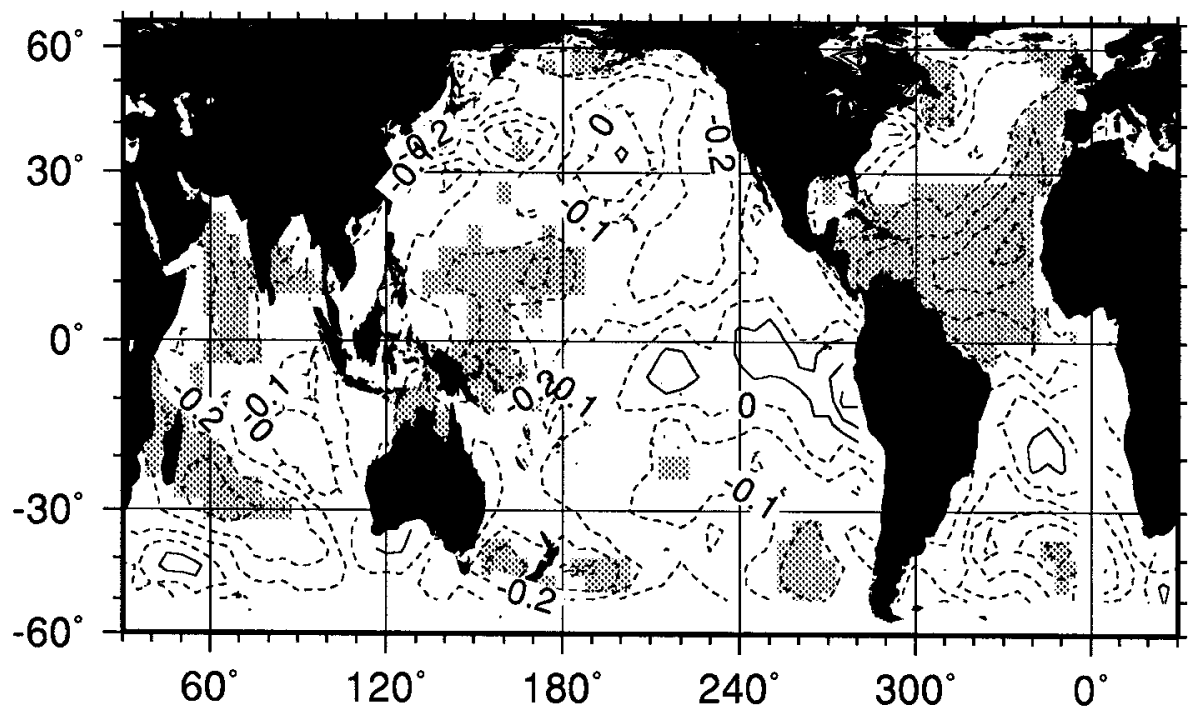

(b) Paraguay-Paraná

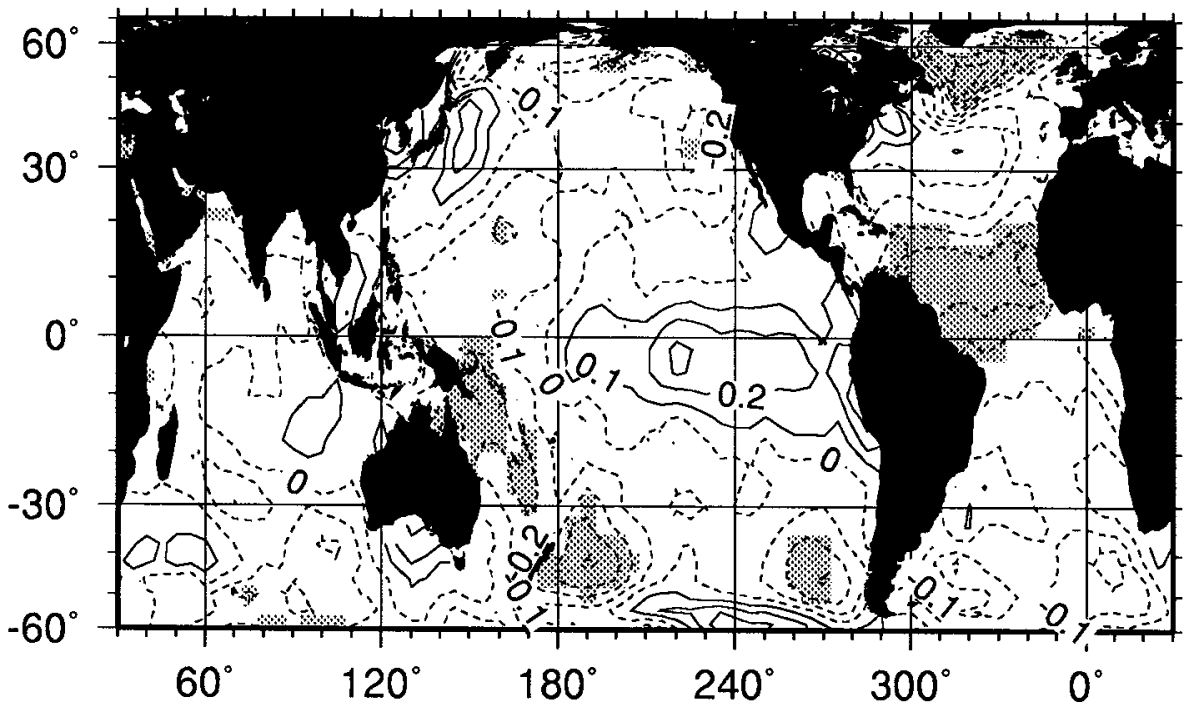

FIG. 12. Composites of SST (annual means) for positive-minus-negative extrema of decadal RCs in Fig. 11: (a) GISST rotated PC 4 and (b) Paraguay-Paraná streamflow. As in Fig. 4. The stippled regions are locally significant at the $95 \%$ level (two-sided $t$ test with 16 degrees of freedom).

ability over the tropical Pacific. Over the South Atlantic, the 6-yr cycle resembles the quasi-quadrennial one in SST. However, the SST anomaly pattern over the tropical North Atlantic is of the opposite sign, with cold anomalies accompanying positive streamflow anomalies.

The upward trend in the Paraguay-Paraná flow time series appears to be accompanied by trends in SSTs of global extent, which are similar to those identified by Moron et al. (1997). The near-decadal cycle is associ- ated with SST anomalies situated over the tropical North Atlantic, with the most statistically significant relationship in austral summer (Fig. 12b). As with the near-6yr period in the Negro-Uruguay Rivers, but in contrast to the 3.5-yr ENSO component, negative SST anomalies in the tropical North Atlantic are associated with enhanced Paraguay-Paraná River flow at the decadal period. This, together with the absence of significant SST anomalies over the Pacific in Fig. 12b, suggests that the atmospheric circulation anomalies that accompany the 


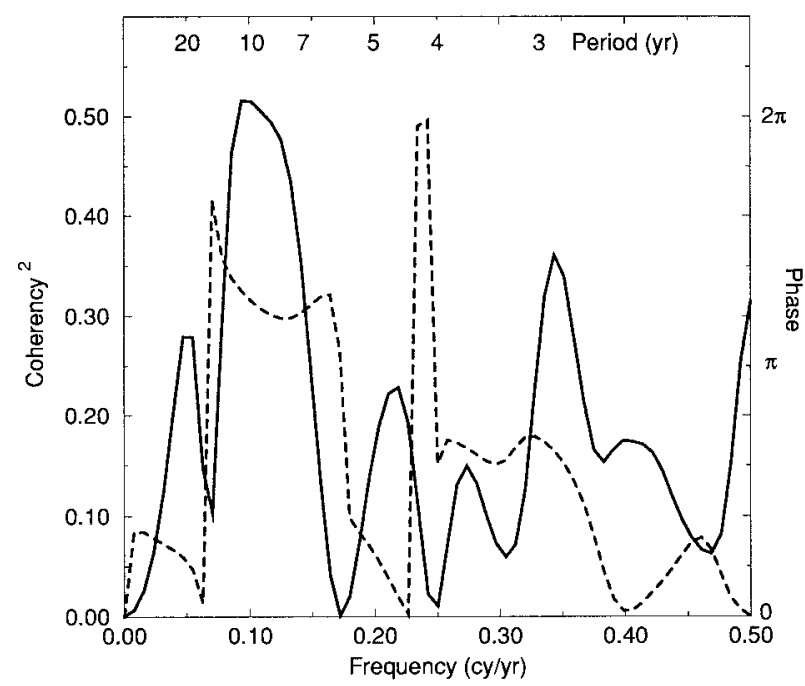

FIG. 13. Squared coherency (solid line) and phase (dashed) of a cross-spectral analysis of the Paraguay-Paraná time series $(x)$ and an index of SST over the tropical North Atlantic $(y)$. The latter was obtained by averaging SST anomalies over the region $0^{\circ}-20^{\circ} \mathrm{N}$ and $60^{\circ} \mathrm{W}-0^{\circ}$. A Tukey window of $20 \mathrm{yr}$ was used, giving a $95 \%$ confidence level for the squared coherency of 0.486 .

9-yr cycle in river flow are very different from those associated with ENSO. No cross-equatorial dipole anomaly in SST appears at any of the frequencies identified here.

One possible path of influence of the tropical North Atlantic on southeastern South America is via decadal variability of the summer monsoon system, and the southward moisture flux associated with the low-level jet along the eastern flank of the Andes (Nogués-Paegle and Mo 1997). Negative SST anomalies over the tropical North Atlantic in austral summer are known to be associated with enhanced northeast trades and a southward displacement of the ITCZ on ENSO timescales (Hastenrath et al. 1987; Aceituno 1988), and also in the 1951-90 linear trend (Wagner 1996). A further intriguing aspect of the decadal cycle in the Paraguay-Paraná Rivers is the apparent covariability with SSTs south of Greenland. This raises the possibility of a relationship with decadal variations in the North Atlantic Oscillation during boreal winter. The remaining challenge is to identify the circulation mechanisms that underlie these interhemispheric teleconnections.

Acknowledgments. It is a pleasure to thank M. Mann for helpful discussions, and both reviewers for their constructive comments. We gratefully acknowledge N. O. Garcia for providing the Paraná and Paraguay streamflow data, and UTE (Usinas y Transmisiones Eléctricas, Uruguay's public utility company) for the Uruguay and Negro River data. This work was supported by NOAA Grants under the GOALS (NAG56022) and PACS (NA56GP0222) programs. This is publication number
4995 of UCLA's Institute of Geophysics and Planetary Physics.

\section{REFERENCES}

Aceituno, P., 1988: On the functioning of the Southern Oscillation in the South American sector. Part I: Surface climate. Mon. Wea. Rev., 116, 505-524.

Allen, M. R., and L. A. Smith, 1994: Investigating the origins and significance of low-frequency modes of climate variability. Geophys. Res. Lett., 21, 883-886.

- , and — 1996: Monte Carlo SSA: Detecting irregular oscillations in the presence of colored noise. J. Climate, 9, 33733404.

Deser, C., and M. L. Blackmon, 1993: Surface climate variations over the North Atlantic Ocean during winter: 1900-1989. J. Climate, 6, 1743-1754.

- , and - 1995: On the relationship between tropical and north Pacific sea surface temperature variations. J. Climate, 8, 16771680.

Dettinger, M. D., C. M. Strong, W. Weibel, M. Ghil, and P. Yiou, 1995: Software for singular spectrum analysis of noisy time series. Eos, Trans. Amer. Geophys. Union, 76, 12, 14, 21.

Diaz, A. F., C. D. Studzinski, and C. R. Mechoso, 1998: Relationships between precipitation anomalies in Uruguay and southern Brazil and sea surface temperature in the Pacific and Atlantic Oceans. J. Climate, 11, 251-271.

Enfield, D. B., and D. A. Mayer, 1997: Tropical Atlantic sea surface temperature variability and its relation to El Niño-Southern Oscillation. J. Geophys. Res., 38, 359-379.

Garcia, N. O., and W. Vargas, 1997: The temporal climatic variability in the "Rio de la Plata" basin displayed by river discharges. Climate Change, 102, 929-945.

Genta, J. L., G. Prerez-Perez-Iribarren, and C. R. Mechoso, 1998: A recent increasing trend in the streamflow of rivers in southeastern South America. J. Climate, in press.

Hastenrath, S., L. C. de Castro, and P. Aceituno, 1987: The Southern Oscillation in the tropical Atlantic sector. Contrib. Atmos. Phys., 60, 447-463.

Jiang, N., J. D. Neelin, and M. Ghil, 1995: Quasi-quadrennial and quasi-biennial variability in the equatorial Pacific. Climate Dyn., 12, 101-112.

Kawamura, R., 1994: A rotated EOF analysis of global sea surface temperature with interannual and interdecadal scale. J. Phys. Oceanogr., 24, 707-715.

Latif, M., R. Kleeman, and C. Eckert, 1997: Greenhouse warming, decadal variability, or El Niño? An attempt to understand the anomalous 1990s. J. Climate, 10, 2221-2239.

Mann, M. E., and J. Park, 1994: Global-scale modes of surface temperature variability on interannual to century timescales. J. Geophys. Res., 99 (D12), 25 819-25 833.

— and signal detection in climatic time series. Climate Change, 33, 409-445.

Mechoso, C. R., and G. Perez-Iribarren, 1992: Streamflow in southeastern South America and the Southern Oscillation. J. Climate, 5, 1535-1539.

Mehta, V. M., 1998: Variability of the tropical ocean surface temperatures at decadal-multidecadal timescales. Part I: The Atlantic Ocean. J. Climate, 11, 2351-2375.

Moron, V., R. Vautard, and M. Ghil, 1997: Trends, interdecadal and interannual oscillations in the global sea-surface temperature. Climate Dyn., in press.

Nogués-Paegle, J., and K. C. Mo, 1997: Alternating wet and dry conditions over South America during summer. Mon. Wea. Rev., 125, 279-291.

Percival, D. B., and A. T. Walden, 1993: Spectral Analysis for Physical Applications. Cambridge University Press, 580 pp.

Pisciottano, G., A. Diaz, G. Cazes, and C. R. Mechoso, 1994: El 
Niño-Southern Oscillation impact on rainfall in Uruguay. J. Climate, 7, 1286-1302.

Rasmusson, E. M., and T. H. Carpenter, 1983: The relationship between eastern equatorial Pacific sea-surface temperatures and rainfall over India and Sri Lanka. Mon. Wea. Rev., 111, 517528.

Rayner, N. A., C. K. Folland, D. E. Parker, and E. B. Horton, 1995: A new global sea-ice and sea surface temperature (GISST) data set for 1903-1994 for forcing climate models. Hadley Centre Internal Note 69, $13 \mathrm{pp}$. [Available from the Meteorological Office, Bracknell, Berkshire RG12 2SZ, United Kingdom.]

Richman, M. B., 1986: Rotation of principal components. Int. J. Climatol., 6, 293-335.

Robertson, A. W., 1996: Interdecadal variability in a multicentury climate integration. Climate Dyn., 12, 227-241.

Ropelewski, C. F., and M. S. Halpert, 1987: Global and regional scale precipitation patterns associated with the El Niño/Southern Oscillation. Mon. Wea. Rev., 115, 1606-1626.

- and - 1989: Precipitation patterns associated with the high index phase of the Southern Oscillation. J. Climate, 2, 268-284.

- and - 1996: Quantifying Southern Oscillation-precipitation relationships. J. Climate, 9, 1043-1059.
Thomson, D. J., 1982: Spectrum estimation and harmonic analysis. Proc. Inst. Electr. Electronics Eng., 70, 1055-1096.

_ 1990 : Quadratic-inverse spectrum estimates: Application to palaeoclimatology. Philos. Trans. Roy. Soc. London, 332A, 539597.

Unal, Y., and M. Ghil, 1995: Interannual and interdecadal oscillation patterns in sea level. Climate Dyn., 11, 255-278.

Vautard, R., and M. Ghil, 1989: Singular spectrum analysis in nonlinear dynamics, with applications to paleoclimatic time series. Physica D, 35D, 395-424.

—, P. Yiou, and M. Ghil, 1992: Singular spectrum analysis: A toolkit for short, noisy, chaotic signals. Physica D, 58, 95-126.

Venegas, S. A., L. A. Mysak, and D. N. Straub, 1996: Evidence for interannual and interdecadal climate variability in the South Atlantic. Geophys. Res. Lett., 23, 2673-2676.

Wagner, R. G., 1996: Decadal-scale trends in mechanisms controlling meridional sea surface temperature gradients in the tropical Atlantic. J. Geophys. Res., 101, 16 683-16 694.

Wang, B., 1995: Interdecadal changes in El Niño onset in the last four decades. J. Climate, 8, 267-285.

Zhang, Y., J. M. Wallace, and D. S. Battisti, 1997: ENSO-like interdecadal variability: 1900-93. J. Climate, 10, 1004-1020.

Zwiers, F. W., and H. von Storch, 1995: Taking serial correlation into account in tests of the mean. J. Climate, 8, 336-351. 